\title{
TRADICIONES DE TACNA
}

Edmundo Motta Zamalloa ${ }^{1}$

\author{
R E S U M E N
}

\begin{abstract}
La fresca tradición oral de los pueblos rurales de Tacna, a cuya escucha se llega al atardecer el dia, nos acercan a su historia, a su moraly a sus costumbres convertidas en relatos para ser transmitidos de una generación a otra. En esa cadena de narradores la historia contada sufre cambios, al ganaro perder elementos, dependiendo de la fidelidad de la memoria y de la habilidad del narrador. Ocurre con los cuentos del pueblo lo que con sus remedios para la salud. Aunque son muchos los que saben de las virtudes de una verba y todos pueden contar los cuentos, hav un diestro curandero para el cuerpo y el alma y un cuentero que conoce mejor las historias del pueblo.

Ofrecemos aqui un adelanto del material de que disponemos, captados en distintos momentos y lugares de los altos de Tacna y tratados libremente por el autor: Para resumir en una frase: son historias del pueblo vueltas a contar:
\end{abstract}

\section{LA LUNA EN EL LOMO DE LAS MULAS}

Una recua de mulas avanzaba en la noche hacia los pueblos del Alto Perú, Oruro o La Paz de Bolivia. A su paso por los valles o en los helados campos de la puna se escuchaban ruidos de cascos, bufidos, gritos del arriero solitario y silbidos con que pretendia corregir el ritmo de la marcha. Tilin tilín tilín, las esquilas de metal que pendian en el pescuezo de la mula madrina enseñaban el camino.

Si el ruido de los cascos despertaba del sueño y hacía pensar en la luna llena, las esquilas hacian imaginar tesoros fabricados con esa plata caminante que juntaba el mar con la cordillera a través de esa modesta mensajera que era la mula. La paz de los pueblos se turbaba por un instante; algún perro saludaba con su aullido desde el patio de una casa sumergida en el paisaje.

Cuando la recua asomó a mitad de la noche tocando apenas por un costado el poblado de Talabaya, alguien que no era precisamente un asaltante de caminos, pero que vivía desde siempre vencido por la ansiedad, se deslizó por una orilla del camino y vio: sobre sus lomos blancos las mulas

\section{Antropólogo.}

llevaban voluminosas cargas que el hombre imaginó con una antigua ilusión.

Aproximó el cuerpo con el sigilo del puma. Por suerte las mulas iban solas, probablemente porque el arriero durmió en alguna parte o se retrasó en algún pueblo con una amante campesina, y las mulas que no podian esperar siguieron su camino. Aprovechó la siguiente curva y apostó el cuerpo tras la sombra de un chañar. Dejó pasar a la mula madrina segura en sus pasos y seguida por las demás que andaban a ciegas tras ella. Cuando no quedaba sino la última, algo fatigada, saltó sobre su presa y la separó del resto. Sin espantarse, las demás continuaron su largo trajinar.

Pobre o afortunado el hombre de Talabaya llevó la mula a su casa, como por descuido.

Liberó las amarras de la carga y ató la mula en un rincón del patio.

Sin saber todavia cómo terminan los raptos, el hombre se echó a esperar que la luna menguara. A poco pensó si era un sueño dentro de otro sueño.

Durmió o no, mientras esperaba esa larga noche, no se sabe. Pero cuando ya habia avanzado el sereno y la Tierra se podia ver en todas sus formas, lo primero que se le ocurrió al hombre de Talabaya fue buscar a la mula. Vaya una sorpresa, a pesar de que no lo era. La mula había desaparecido. 
Cabizbajo, el hombre estaba seguro de que habia soñado, que la mula no era más que un sueño, y bien sabia que las mulas en el sueño anuncian un largo viaje, a tierras muy lejanas. No había ni una huella de que hubiera dejado alli, amarrada al horcón, una mula, o algo parecido. Ya más convencido de que a veces los sueños son más reales que la vida, dirigió por un caso sus pasos al lugar donde pensó (o soñó) haber dejado el cargamento. Estaba casi seguro que habia desaparecido con la mula. Caminó como quien no quiere andar, y !Oh, sorpresa! Ahi estaba el cargamento que no era de tocuyo, lanas, ni cebada, ni aceituna, sino duros de oro y plata y hermosas joyas con extraños adornos. El hombre de Talabaya dio un paso atrás, otro adelante, temeroso palpó los metales que no se esfumaron entre sus dedos, pero estaba tan seguro que eso no podia ser sino un sueño, y lo siguió siendo aún cuando brilló sobre los metales toda la luz del sol.

Lo real es que la mula habiadesaparecido sin dejar un rastro, y lo ilusorio que aquel oro y aquella plata tenían ley propia. El hombre permaneció oculto en su casa algunos años sin animarse a confesar su sueño; pero tal vez en espera de que se presentaran sus legítimos dueños desde algún lugar de la Tierra. Los años siguientes siguió oculto extremando su vigilancia para evitar que otros le arrebataran su sueño.

En las silenciosas calles de Talabaya empezaron a aburrirse con la misma historia. ¿Cómo era posible que un hombre tan cuerdo como Lucas haya podido tocarse de la cabeza, asi tan de un día para otro? Daba lástima y despertaba cólera pues ya no ayudaba en los cultivos y se habia vuelto inútil en el pueblo. Aislado del mundo, Lucas vivia en la sombra de su casa, flaco como un esqueleto, sobreviviendo apenas con algo de comida que una anciana caritativa le llevaba de vez en cuando. Por ella es que sabian que Lucas no sólo estaba raquítico, sino feliz.

\section{LA LLAMA CELESTE}

El hombre se había despertado de súbito. Nada alrededor lo perturbaba, ni un ligero ruido, ni el más leve movimiento que insinuara la sombra. Sin embargo, tenía los ojos abiertos, su cuerpo se alargaba totalmente reposado sin los aprontes de frio o calor. El hilo de plata que cruzaba la oscuridad no hacia más que confirmar que aún estaba lejos el amanecer. ¿Lejos? Tal vez andando podía darle alcance. No importa si se topaba con el ronco, o le siguiera los pasos el arriero fantasma, o le alcanzaran los lamentos de alguien que todavía no habia atravesado el rio de la muerte. Se vistió y quiso salir, caminar aunque sea al partidor de Irabalaco, nada más que por ir y caminar, haber si el andar le devolvia las ganas de dormir. Abrió la puerta, de prisa, y se encontró con la tierra dormida, llena de oquedades negras y de árboles plateados por la luna. Se distinguia el camino, apenas un rasguño de serpiente echada más arriba del canal de regadio, huyendo de la quebrada. Si los pies no se habian echado a andar fue porque algo impreciso lo contuvo, algo como la idea de aguardar la proximidad del alba y acaso el brote de los pájaros cuando se desperezan en los árboles. Algo impreciso posaba la mano en su pecho, aunque otra más imprecisa aún lo empujaba por la espalda.

La ansiedad acortó el camino; hizo salir el sol antes de lo acostumbrado. Delante del estropicio en que habian convertido su parcela despertó por segunda vez como después de un prolongado sueño. Transpiró. Las rodillas tremolaron como hojas secas al descubrir sobre las melgas frescas y húmedas, extrañas, reales y palpitantes marcas de Ilama, inconfundibles pezuñas que terminaban en punta e iban siempre en parejas. Su rabia se hizo más grande al comprobar que en las demás parcelas el aire soplaba cultivos intactos y sólo a él, a Kuwa lla, habian elegido quien sabe por que oscuras intenciones. EI filoso perfil de acero protegido por la funda de cuero se alzó en el aire, y guió al hombre por insospechados atajos buscando cuerpos de llamas que estarian rumiando ocultas bajo algún árbol.

No sólo la tierra no había retenido los rastros que buscaba; tampoco sabian nada en el pueblo, y menos que hubieran visto una llama ni presentido su olor a yareta fermentada por algún sitio. A menos que fueran los animales de Eladio Chura y Urelio Laura, cuyas majadas se habian deshabitado el último dia para el traslado de coca y sal, pero que habian pernoctado en apriscos de adobe y piedra, y el pastor en la puerta, por un caso. ¿De qué los acusaba Kuwa lla? ¿Mentia o se estaba volviendo loco? De todos modos les quedó la duda a Eladio Chura y a Urelio Laura; si no fueron animales de alguno de ellos, entonces habia que escucharle a Kuwa Ila, no fuera que después les ocurriese lo mismo, y nadie sabía nada. $Y$ más por entender aquello que estaba empezando a parecer un misterio, lo acompañaron.

Con aire que se les amontonaba en el pecho vieron las papas pervertidas por menudos cascos, dispersas por las melgas. Recorrieron con piernas asustadas el contorno de la chacra convencidos de que la seguridad no dependia sólo de la altura del cerco. 
--No se ve ningún portillo por ninguna parte-- dijo Urelio Laura.

Kuwa lla reparó en el detalle. Efectivamente, no habia ningún portillo, avivó los ojos para estar seguro de que no habia ningún portillo, ni huellas de que hubieran reconstruido el cerco. Y el cerco tenía casi la altura de un hombre plantado en sus pies como para pensar que una llama, asi fuera de las majadas de Huaytire, podría vencer el cerco sin haber dejado en la arista un mechón de lana.

Se quedó solo, como en la madrugada, viendo que los demás se marchaban también pensativos. A su lado caia, pesado e inútil, el cuerpo de acero.

Esa noche sus párpados volvieron a velar, espumosa la boca rumiaba el fuego de la cólera. Le molestaba sobre todo la idea de que los depredadores de su parcela se estaban escapando sin que pudiera identificarlos.

Más despacio que en la madrugada anterior cerró la puerta de su casa. No quería despertar a los perros que podian despertar a los hombres, no queria que sospecharan que Kuwalla andaba detrás de los espiritus. Encima de todo, que nadie perturbara su deseo de desenredar un engaño. Así es como el hombre y el alba se encontraron en la parcela.

Ýa no era oscuro y el sol estaba por salir, pero la noche se habia quedado en su chacra. Otra parte de papas se había perdido de la misma manera. Sus ojos recogieron de nuevo aquellas huellas ,idénticas, recién puestas sobre las melgas. Y otra vez comprobó que el cerco continuaba entero.

Mudo como la piedra subió donde Vinchak, sin hacer ni responder preguntas de gentes que habian salido a la colina a cazar algo de la tibieza de sol o andaban ateridos de frío por las umbrosas y retorcidas calles del pueblo. Pasó de largo, furioso, con el puñal y la botella de aguardiente que se bamboleaban a sus costados.

Al llegar a la torre reconstruida del viejo templo, cuyo techo coincide, allá arriba, con el extremo de los eucaliptos más altos, y desde donde se domina el reposo del cementerio, levantó una tranca de aliso y entró como en su casa.

Vinchak oyó sus quejas. Sin dejar de chacchar coca, sin hacer gesto alguno. Entre los dos estuvieron hablando el día completo sobre las maldades del hombre.

--Si vinieron dos noches seguidas, es seguro que volverán una tercera vez.

Kuwa lla se decidió. Si ese año, como estaba visto, no tendria ni semillas para la próxima siembra, podia al menos cortar carne, torcer vellón de lana para hacer mantas o sogas, y cuero con que cubrir el asiento.

--Te daré las cabezas, no me gustan los ojos muertos de la llama.

Desde que se fue el Sol estuvieron los dos solos en la orilla del acueducto, ocultos por la sombra de un molle, hablando quedo. Renovaban coca para no dormirse, de rato en rato volteaban una copa de aguardiente para darse valor.

La noche subió con racimos de estrellas. Sobre el Barroso una antigua luna sonrió. Vinchak se arrastró un trecho para tener libre la visión del cielo. Se quedó contemplándolo con un regocijo infantil, reconociendo cada cosa como en un gigantesco mapa desplegado sobre una sábana negra.

--Esa es la Cruz del Sur --apuntó Vinchak--, este año habrá bastante lluvia porque va derecho al Kumayli.

Kuwa lla entristeció. «Si», pensó, «que llueva mucho».

--Aquél montón de estrellas alargado encima del Gran Lago dicen que es una llama-- volvió a decir Vinchak.

Kuwa lla irguió el tronco para fijarse mejor en esa constelación que bien podia tener la forma de una llama, aunque le resultaba imposible distinguir la cabeza, el cuello, las patas. En medio de confusas luces sólo se podía ver el perfil de un cuerpo prolongado que se hacia más estrecho en el confín del cielo. Algunas luces acababan de encenderse y quizá después apareceria la llama que decia Vinchak. Era la paz completa en la Tierra. Las oquedades donde no alcanzaba a iluminar la luna dormian un sueño profundo, los nevados del Barroso resplandecian aún más.

Atrapadas por el silencio las estrellas tejian su propia fiesta. Una de ellas que parecia perder quietud llamó la atención de Kuwa lla. Mientras que las demás permanecian imperturbables en su lugar, esa otra vibraba o empezaba a vibrar describiendo un paso tan breve, apenas perceptible. Como si no hubiera encontrado sitio, o más bien como si la hubieran rechazado, trazó una curva larga por debajo de la constelación y fue cayendo por todo lo ancho del espacio a perderse raudamente detrás del nevado de 


\section{Caparaja.}

Una sensación de temor acudió a su corazón. La estrella habia caido cerca de donde estaban ellos y bien podria convertirse en un gran incendio.

--!Ahi está!-- exclamó Vinchak.

Todavia estaba en su memoria aquella estrella cuando Kuwa lla entrecerró los ojos y vio una llama blanca que devoraba apaciblemente las papas de su parcela.

La visión duró una eternidad. Era tan blanca como la nieve, tan brillante como una estrella, pero devoraba las plantas como cualquier animal de este mundo.

---!Tras ella!-- se animó Kuwa lla sacando de sus adentros un rencor oculto. parcela.

Para no espantarla, pasos sigilosos orillaron la

La llama levantó la cabeza; ágil y desconfiada se quedó inmóvil todavia con una rama de papa entre los belfos. El mundo se detuvo, todo ruido fue atado y sólo el resplandor de luna habitaba la noche, hasta que el hechizo cedió al paso de la llama blanca que salvó el cerco y echó a correr sin dejar rastro en la tierra de su luminosa huida.

Sus perseguidores tropezaron con cercos, plantas, arbustos; llamándola a grandes voces, poseídos por la fuerza del cazador invencible estuvieron corriendo a través de las terrazas, el campo abierto de yaretas y pedregales, cada vez más cerca y más lejos del animal fugitivo, listos para arriar el laso o disparar el puñal. Las horas se consumieron en minutos con la misma seguridad con que la llama fugitiva equivocó de sendero y en vez de fugar por la pendiente de los queñuales entró por el abrigo de las peñas de Cauruni. Se detuvo un momento brevisimo, lo suficiente como para que sus perseguidores pensaran que ya la tenían cautiva, pero en aquel mismo instante, cuando más cerca estaban de nada, la tierra se fue alejando por lo bajo, cada vez más distante, mientras la llama blanca, vuelta hacia ellos con sus enormes ojos de piedad, se elevaba y cruzaba por la mitad de aquella lámina de granito como quien atraviesa el agua o el aire. Su intenso brillo fue disminuyendo de tamaño hasta ser nada más lo que era: un punto de luz, navegante de los tiempos, encima del Gran Lago.

\section{LOS SONIDOS DEL BRONCE}

Cuando empezó la guerra, los chilenos venian por la estepa del Barroso, corriendo a pie o desbocando sus caballos. Se apropiaban del agua, de la tierra, del aire, de los rios, de los pájaros. Decian que su pueblo comenzaba en las tierras del fuego y atravesando el tiempo terminaba en los extremos del hielo. Asi era Chile, un gendarme con botas de matar, y sable con que daba pasaporte a las aguas del poniente.

--Dios te salve, Tarucachi.

No era tiempo de truenos y el río bajaba mudo. El viento sólo arrastraba un remolino de sables y el rebuzno de cazadores. El mundo se encerró en un pequeño círculo. La sangre quería reventar en las venas. El sol los abandonaba.

--Dios te salve, Estique.

El cura Demetrio Rosas se dolió por la estatua de San Benedicto de Abad, por la Virgen del Rosario y la de la Concepción, por los objetos litúrgicos de oro y plata, por las campanas de bronce legítimo. Sintiendo doblarse, dejó que se fuera en la espalda de su fiel cocinera el pequeño crío que todavía no alcanzaba a decir papá. Pero sus ojitos inocentes parecian entender que el hombre de Dios sólo era carne desgarrada que se marchaba por el camino de la estepa en vez de venir junto con todos los que podian cruzar las aguas del rio Ticalaco, apurados en salvarse de las raices del sauce.

De todos los que huian despavoridos porque el enemigo no dudaba en pasarle el sable cuando encontraba un obstáculo, por pequeño que fuese, diez rostros pálidos, los últimos que el Cura vio en el pueblo se enfrentaron a los designios de la suerte, tal vez empeñados en demostrarle al Cura que la fe no sólo mueve montañas de piedra sino que era capaz de llevarlos a la gloria sin ser heridos de muerte.

Cuando todo habia acabado, el Cura se sintió invicto y más lúcido que nunca lloró al pie de la campana sepultada cuyos dobles no volvería a oirlos quien sabe hasta el dia en que los ángeles lo llamaran de la muerte. Pero tenía al menos la seguridad de que las estatuas divinas velarian desde las raices del sauce por los débiles que quedaban al desamparo sobre la tierra. Por si extrañaran los domingos, los dejaba en custodio el cáliz de oro, los candelabros de plata, las pinturas del siglo dieciséis.

Oró la noche sentado sobre una solitaria piedra y el día pareció tan incierto como el camino que lo extravió cuando tuvo que responder a un insolente gendarme que se iba del mundo expulsado de sí mismo.

Así que los chilenos encontraron un pueblo sin 
habitantes, casas sin puertas, un templo sin santos, una torre sin campanas, una serpiente de aguas sin voz, un silencio sin nacimiento y $\sin$ fin.

Y cuando esas tierras fueron devueltas en 1925 , los sobrevivientes retornaron a reconstruir la historia de sus dominios. Los más viejos llevando el recuerdo de sus muertos, los más jóvenes con la ilusión de estar conquistando un mundo, subieron a Tikajasa para desenterrar en principio la campana, convencidos de que al oír sus dobles volverian los muertos a la vida, los ausentes a su pueblo. Sólo que les habría de costar muchos años de búsqueda sin encontrar huella de que el suelo fuese profanado y sí, en cambio, la idea firme de que también el bronce con ser metal se derretía en el subsuelo igual como se pudre la carne.

Tan igual como la carne que tuvo voz, el bronce que tañó durante cientos de años convocando a las almas para acompañar las celebraciones del Cura volvió a ser oído en el territorio restaurado pero de un modo distinto que sólo podían oírlo las gentes que ya estaban con un pie en el otro mundo, cuyo tañido en el momento de la agonía era anuncio inequívoco de que estaba listo para seguirle los pasos del Cura por la estepa interminable del Barroso.

\section{EL REVÉS DE LOS PASOS}

Con la plata que explotaban los españoles, tan clandestina como la mina de Andamarca que desfloraban, no sólo convirtieron en barras con los que adoquinaban las veredas de sus casas, en cerrojos de bellos motivos que pendian en las porterias, en ley de todo lo que fuese metal desde utensilios de cocina hasta los enchapes de las sillas de montar, pasando por los candados de castidad y las espuelas de montar, sino que dieron pose y soltura al comercio convertidas en monedas selladas con el nombre y figura del español andamarquino de más valor que el peso ensayado que venian allende las montañas regimentadas por el Virrey.

Claro que las noticias llegaron a oidos del representante del monarca en tierras del nuevo mundo aunque tardaron varios años siguiendo una cadena de postas de legendarios arrieros y veleros que dieron por efecto que el Virrey enviara a su lugarteniente para averiguar la verdad y descargar sobre los falsificadores de su nombre la justa ira de Dios. Pero avisados con tiempo por los chasquis que habian aprendido a dominar el caballo mejor que los mismos mensajeros del Virrey, los mineros de Andamarca afiataron la plata en una larga recua de mulas, pues estaban convencidos de que un pleito con Dios y su representante en la tierra era una guerra perdida desde el comienzo, y decidieron por una vez y para siempre jamás irse a tierras sin bautizar y por caminos sin explorar como auténticos profetas de aquel poeta que cuatrocientos años después rezara para la memoria de la plata y el oro «caminante, camino se hace al andar", y así partieron con destino a Bolivia como dejaron dicho a los asombrados testigos que los vieron partir al encuentro de la Luna. Lo que nadie habia sospechado entonces era que los fugitivos andamarquinos habian cuidado de colocarles a las mulas los herrajes al revés, de modo que siguiendo aquellas huellas impregnadas en el barro sus perseguidores supieron que en vez de dirigirse hacia Bolivia habían tomado la dirección contraria.

Las mulas que se fueron, venian. Dos habian rodado con su cargamento de plata al precipicio ahogado por el río Toquela. De eso supieron muchos años después, cuando el andar convirtió el paso de las mulas en viejo camino, y se oía en el fondo del precipicio, a mitad de la noche, un relincho verdadero de mulas y los tumbos de una caída peñas abajo hasta reventar en el estallido del agua, mientras que otra mula tan verdadera como la Luna menguante aguardaba con los ojos vacios encima de la barranca. Iba y venia hasta que el sonido y la visión entraban en silencio.

\section{EL FUEGO DE SAN JUAN}

Claudio cumplió veinticinco años durante el solsticio de junio, más exactamente a las ocho de la noche, la única noche que se puede saber la hora exacta porque se da inicio a la fogata de San Juan en la plaza del pueblo. A diferencia del fuego encendido en otras fechas del año, éste, el del solsticio de junio, que coincidia con el inicio del invierno, tenía un objetivo que los hombres más viejos se encargaban de recordarlo: habia que evitar que el mundo se sumergiera en las tinieblas del frío y, de paso, se estimulaba la procreación de los corderos en los potreros de Carumas.

A esa misma hora, hace veinticinco años, dos horas antes de morir de una puñalada al corazón, su padre contemplaba las lenguas de fuego, mientras que su mujer se retorcía con los dolores del parto tirada sobre un pellejo de cordero.

Le ocurría cada solsticio de junio, su nacimiento anticipaba la muerte de su padre. Por alguna razón el fuego de San Juan tenía la virtud de trastocar el orden de las cosas. Lo supo varios años después, quizás 
tanto como su padre horas antes de morir, cuando vio que no habian oídos que le oyeran, ni ojos que lo vieran, ni voces que le hablaran, dejándolo en un silencio miserable y evitándolo como pudieran. Los hombres le despreciaban, las mujeres trazaban cruces en el aire como si hubieran visto al diablo en persona y hasta los muchachos que antes lo buscaban para que les enseñen a enlazar el trompo, sólo como él sabia hacerlo, ahora se corrían como del perro rabioso o se hacian a un lado como del chancho con sarna. Había nacido para el escarnio, cosa que no le importó en lo más minimo, salvo meses después, cuando aquello ensombreció a su madre y a su hermana, quienes habian decidido no salir a la calle, ni siquiera para comprar un terrón de azúcar, así tuvieran que morirse en ayunas. Entonces tomó conciencia de cuanto habia hecho y pasado, quizá como en juego, con su voluntad o sin ella,tal vez porque asi son las cosas para algunos justamente porque asi no son, y tuvo miedo de si mismo y poco después una gangrena incorpórea empezó a pudrir su alma. Al atardecer encontró en la cocina a su madre y a su hermana bañadas en llanto, culpándose entre sí, y con espanto notó en sus rostros, como si se viera ante un espejo, que ellas tambièn se estaban pudriendo por dentro.

No habian necesitado pronunciar una palabra más, ni dejar mensaje alguno para nadie. Se sentaron frente al fogón de brasas vivas con la mirada seca en las llamas perpetuas.

Esa misma noche dos piadosos hombres tuvieron que hacer varios viajes al pequeño camposanto del pueblo. Sin acompañamiento alguno, como corresponde en los funerales, les dolía en el alma tener que echarles unas paladas de tierra sobre sus cuerpos todavia calientes. Sin embargo, lo que más les molestó no fue que incendiaran la casa de Claudio, sino que nadie creyera que los habian enterrado; aunque lo único que podian ofrecer como prueba en contrario era la tierra revuelta del camposanto.

También lo supieron los lugares descampados, hacia el atardecer o cuando sobrevenía una noche de luna o se desataban las furiosas lluvias de la temporada, pues los desprevenidos solian verlos (juraban verlos) vagando a campo traviesa. Lo que entonces miraban no era más que un hombre con los ojos vacios que llevaba atadas por el cuello a dos perras. El hombre debia ser Claudio y las perras corresponderían una a la madre y la otra a la hermana. Andaban atados en la muerte como antes estuvieron en vida soportando los escarnios del pueblo. Según los designios de Dios, su condena consistía en caminar por los derroteros del mundo, abarcando sin prisa ni descanso sus extremos y cercanias, hasta que a fuerza de caminar se les acabaran los pies; es decir, para siempre.

\section{LA CABEZA QUE RUEDA}

Cuando la vio por primera vez el pueblo estaba de fiesta y ella de chapera. Al igual que otras mozas, entre las que se contaban también mujeres mayores, se distinguian de las demás por sus encendidos trajes de colores y el aguayo cruzado al pecho en el que llevaban hojas de coca y pétalos de clavel. Iban y venian ellas provistas de chicha, aguardiente o cerveza, de papas o carne asada en carbón de piedra viva, abriéndose paso a duras penas en medio de un gentio siempre dispuesto a adelantar o repetir una copa o un bocado más.

Al rato supo Sixto Mandamiento que la más joven de las chaperas era celebrada por los muchachos disfrazados o no de diablos, músicos o simples caminantes de feria, y que sus pasos eran seguidos por ansiosos ojos bañados en aguardiente. Verla de pronto delante suyo con el brazo extendiendo una Pilsen fue para Sixto algo asi como un regalo de la Santa Patrona de Candarave, cuya fiesta habia concentrado a medio pueblo en la casa del alferado.

La volveria a ver en la tarde, durante el "entradero», alcanzando vino a los conductores de autos, camionetas o a los jinetes que iban a caballo con sus terciados ponchos de vicuña y sombrero blanco. Fue precisamente por uno de aquellos jinetes, inclinado sobre la montura de su ágil alazán para levantar el sombrero y agradecer el apetitoso vaso de vino, que supo que ella se llamaba Flor de Margarita y él, Melquiades.

Si no esa misma noche, fue al día siguiente que el silencio volvió al pueblo, el templo cerró sus puertas, la casa del alferado se llenó de desperdicios, los hombres volvieron a las cendas tras los pasos de sus bueyes y corderos, y las mujeres a dar vueltas en torno al fogón. Sí, esa era la sierra, después de la fiesta una silenciosa y fría plaza el resto del año.

Como dijo el sargento Antonio Contreras, habia en realidad muy poco pleito; a veces se preguntaba si era necesario un destacamento de policias en un pueblo tan pacífico, pues aparte de perseguir a algún abigeo que venía como el zorro del otro lado de la cordillera, en este pueblo no pasaba nada. Uno que otro maltrato derivado del lío entre marido y mujer, un robo que más parecia una broma, o que se negaban a pagar la cenada de los domingos, eso era todo. Uno se pasaba el día 
bostezando; sin pleitos la ley no daba dinero.

Sixto Mandamiento todavia se estaba acostumbrando a una situación en que todo era nuevo para él, empezando por su uniforme bajo el cual se sentía como otro hombre, y ese pueblo de vientos helados que eran un desafío para alguien que, como él, venía de la costa dispuesto a imponer justicia ,si no como el llanero solitario, al menos como cabo de segunda, y más ahora cuyo pensamiento lo ocupaba Flor de Margarita. La tarde que ella fue a visitarlo en la propia comisaria, sin nada convenido, como quien acude a preguntar por el estado del tiempo y ofrecerle su ayuda en caso que lo necesitara, Sixto se habia emocionado tanto que por poco se puso a llorar, pues no se habia equivocado que él también ocupaba algo de los sueños de Flor de Margarita.

Por un tiempo fue ella la que fijaba las citas, día y hora, como si estuvieran en una ciudad y no en un pequeño pueblo a más de cuatro mil metros sobre el mar, donde el reloj no marcaba el paso de las horas, sino la eternidad del tiempo. De no ser porque el lugar era siempre el mismo, la casa donde Flor de Margarita vivía sola, acompañada apenas por los ladridos de un pequeño chusco, Sixto no habria esperado tanto tiempo para imponer la cita largamente acariciada que ella acabó por aceptar desechando los brazos que buscaban atarla en el aire. $Y$ fue justamente un viernes de cielo estrellado que Sixto subió el cierre de su impermeable y atravesó la angosta y retorcida calle que bordeaba una cenada de alfalfa.

Recortada contra la oscura silueta del Yucamani encontró la casa de Flor deMargarita. Y al contrario de lo que pensaba, ninguna luz la animaba, ningún ladrido estaba al acecho. Sixto respiró el desaire, caminó por el patio dando silbidos, estrelló una lata en el corredor oscuro, tosió; pero no obtuvo ninguna respuesta.

Poco después la furia de su alma se calmó en el pasillo oscuro donde habia un banco de tierra al que pudo llegar a tientas.

Cuando más convencido estaba que por algo a Flor de Margarita le gustaba fijar las citas, Sixto se frotó las manos al percibir unos pasos que atravesaban el patio. No habia sido en vano su espera de casi dos horas, pero tan pronto como estuvieron en el corredor supo que aquellos pasos correspondian a otro hombre, en cuya voz, tono y turbación de su alma, reconoció nada menos que a Melquiades. Dejó que avanzara en la penumbra con las manos alzadas como un ciego hasta que se sintiera descubridor y descubierto a la vez. La oscuridad que helaba ayudaba tal vez a hablar lo necesario y terminó dejando atadas en los bolsillos las manos de ambos pretendientes. Heridos o no en su orgullo, callaban prolongadamente, llenándose en sus silencios de preguntas y respuestas.

"Flor de Margarita es mi prometida desde mucho antes que llegaras a este pueblo", se dijo Melquiades.

"Mia tendrá que ser, por algo llevo uniforme", oyó en sus adentros Sixto, como un trago amargo.

Cada vez que el aire arrastraba un ruido desde el patio, ellos pensaban que llegaba Flor de Margarita. Pero conforme avanzaba el tiempo parecía definitivo que no llegaba. Sabiéndose en falta, quizás, habria decidido pasar la noche donde alguna amiga o un pariente. ¿Se imaginaba el escándalo que se iba a armar en su casa? Sixto rasgó una cerilla para comprobar que estaba a punto de ser las doce de la noche, cuando apareció de súbito aquella luz, blanca como una estrella, que atravesó el corredor y entró por la ventana a la habitación de Flor de Margarita. Un leve ruido acompañaba a la luz.

Sixto y Melquiades estaban asombrados y pronto el temor se apoderó de ellos. La luz que había entrado en la casa, volvió a salir por el mismo sitio, pero esta vez sin hacer ruido.

Por un momento Sixto sospechó que entrando por esa ventana podría encontrar a Flor de Margarita. Sobreponiéndose al miedoadelantó un paso en la oscuridad, como un ladrón cualquiera, y empezó a mover las manos, buscando a tientas la pared, encogiéndose por un caso tropezaba con los objetos, casi hasta tocar el piso; un poco hacia la derecha palpó el lecho y explorándola dio con el cuerpo de alguien que reconoció en el acto. Todavía esperó que reaccionara pensando que si no estaba suspirando Melquiades del otro lado de la pared se habria tirado sobre el calor de ese vientre palpitante abandonado a su suerte. Y sólo después de haber comprobado que el sueño de aquél cuerpo se parecía a la muerte buscó donde creía que estaba la cabeza y palpó el final del cuello. Entonces salió despavorido y alterando en su huida la inicial posición de la durmiente.

Melquiades tambaleó conteniendo a duras penas con los brazos abiertos, pues Sixto parecía un potro en estampida con la garganta llena de resuello. Pero el aire que empezaba a faltarle a Sixto cuando queria hacerse entender amenazaba también dejar mudo a Melquiades

Y no habian tenido tiempo siquiera de reponerse 
cuando volvió aquella luz blanquecina destinada a jugarles el mismo partido. Como antes, entró por la ventana, pero no tan segura de sus alas porque enseguida se oyeron unos lamentos de mujer que los amantes no dudaron en reconocer. Tras los lamentos, la luz blanquecina salia y volvía a entrar por esa ventana, extraviada, hasta que creyó encontrar su órbita delante de Sixto. movido.

--Entra y deja mi cuerpo como estaba, que lo has

Habló esa luz, la siempre metálica voz de Flor de Margarita.

Sixto tembló mucho más porque esa luz parpadeó como un ojo que clama ayuda y la propia voz conocida que le habia hablado por fin, a él y no a Melquiades, llegaba desde el cuerpo o la luz en tono de súplica, si bien parecia una orden que se imponía a toda fuerza y era superior a toda voluntad. Sixto volvió a encaramarse por la ventana y caminó en la pesadez de un caldo frío, alzando apenas las manos pero escondiendo los dedos como si tratara de evitar el filo de una navaja, queriendo con toda su energía no despertar nada o a nadie, si es que de verdad habia alguien, hasta dejar aquel cuerpo palpitante como pensaba que hubiera estado al comienzo.

Después, Sixto y Melquiades se alejaron. Al abandonar la casa alcanzaron a ver aquella luz que retornaba a la habitación de Flor de Margarita.

El resto de la noche Sixto pasó en blanco, atormentado por la idea de haberse encontrado con el cuerpo y la voz de Flor de Margarita pero no con ella. Esperó que se hiciera alto el sol, para hacerle una visita, aunque fuese la última que más que a nadie le hacia falta a él.

La encontró sentada en el patio ordenando su larga y enredada cabellera.

Bastaba para Flor de Margarita verle la cara de susto, los ojos que no salian de su asombro, aunque no expresaba rencor alguno, para darse cuenta que Sixto no estaba herido en su hombría, sino algo más profundo que eso, le habian alborotado el alma. Ella pidió disculpas, aunque no sabía exactamente por que.

--Pero... anoche...Melquiades...yo...

Flor de Margarita echó el busto para atrás.

--Lo siento --dijo-- me tocaba "volar». Rezo dos veces por semana oraciones que me enseñó mi madre, hasta que logro desprender la cabeza de mi cuerpo y entonces voy al encuentro de quienes están en mi odio, libre de toda atadura, sin que nadie pueda reconocerme, dejando mudos a los curiosos, peleando con los de mi especie, aceptando a veces si me invitan aji con sal...

Ella gozaba mientras hablaba, viéndose el cabello por retazos en el pequeño espejo que sostenía en la mano.

Sixto Mandamiento se alejó pensativo; permaneció un tiempo sin animarse a contar su historia. Poco después fue transferido a la costa, a un barrio marginal donde por las noches llueve arena e impide la visión de las estrellas.

No siempre. Alguna noche trepó al montículo de arena y vio, o creyó avizorar, una luz viajera al pie del volcán Yucamani. Entonces pensó en Flor de Margarita, con cierta nostalgia.

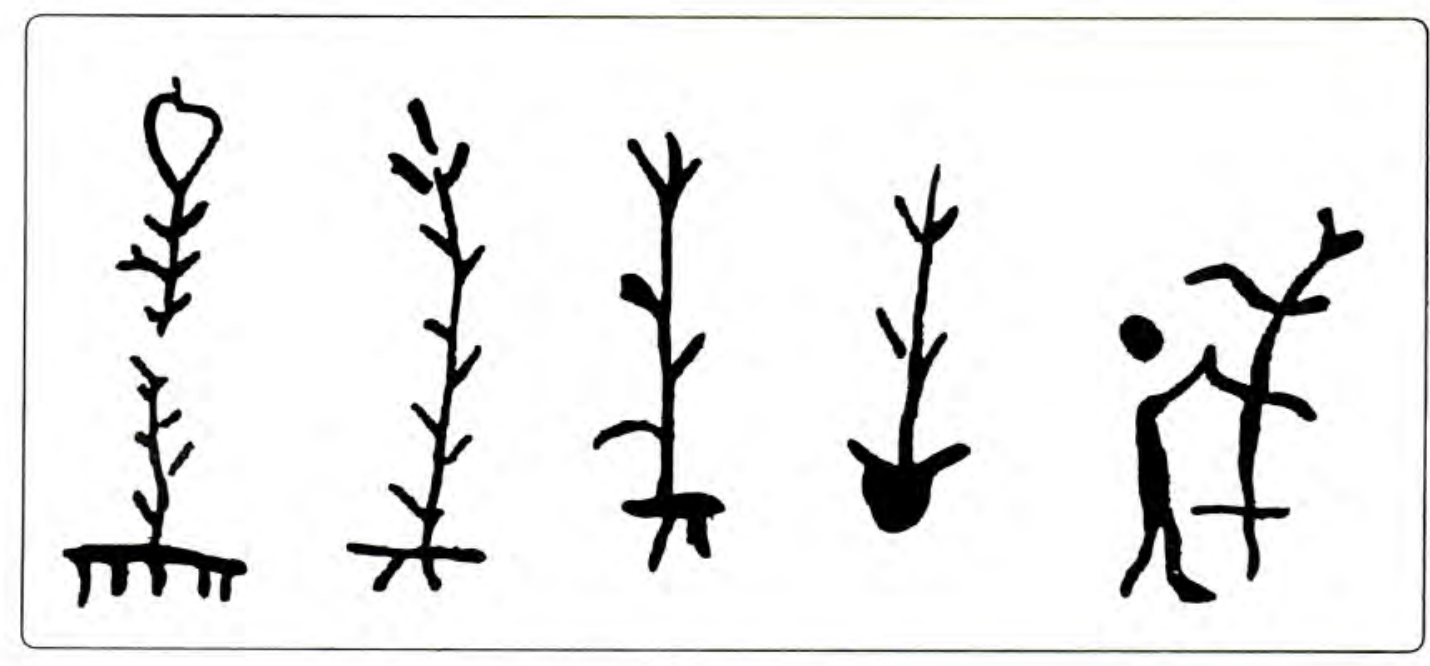

Tallos y raices 


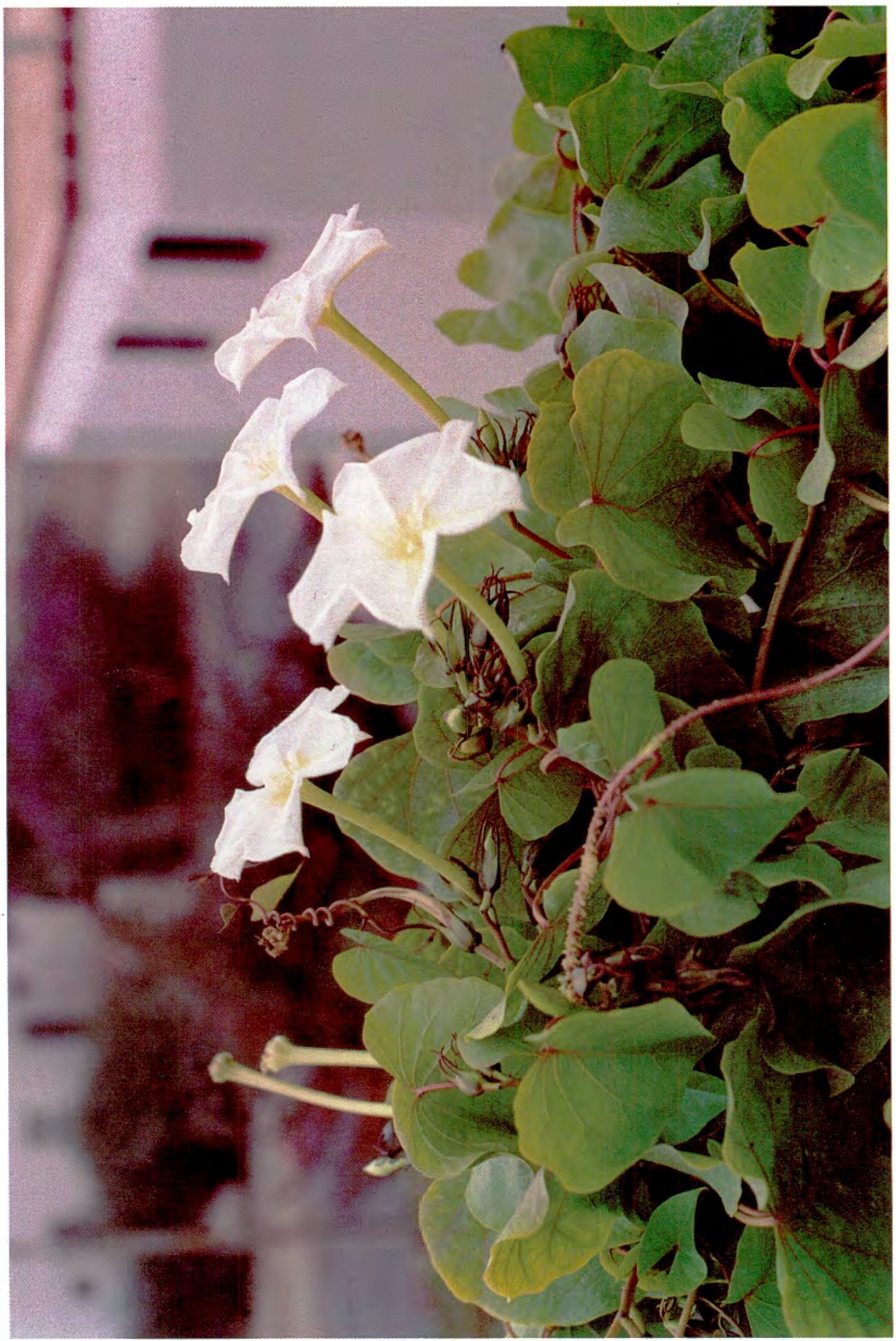

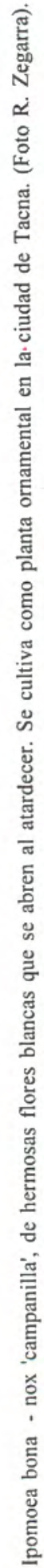

